\title{
An Analysis of Rainfall Measurements over Different Spatio-Temporal Scales and Potential Implications for Uncertainty in Satellite Data Validation
}

\author{
D. N. PIYUSH, Atul Kumar VARMA, P. K. PAL \\ Atmospheric and Oceanic Sciences Group, EPSA Space Applications Centre (ISRO) Ahmedabad, India \\ and \\ Guosheng LIU \\ Department of Meteorology Florida State University, Florida, USA
}

(Manuscript received 20 September 2011, in final form 24 March 2012)

\begin{abstract}
The work presented herein deals with the problems of inter-comparison of precipitation values at $8 \mathrm{~km} \times 8 \mathrm{~km}$ and $4 \mathrm{~km} \times 4 \mathrm{~km}$ scales (herein often referred to as $8 \mathrm{~km}$ and $4 \mathrm{~km}$ pixel or scale) that represent the approximate instantaneous field of view of thermal infrared measurements from geostationary satellites like Kalpana, Geostationary Meteorological Satellite (GMS), etc. A number of temporal, spatial and spatiotemporal precipitation series at 4 and $8 \mathrm{~km}$ scales from TOGA-COARE radar observations are subjected to autocorrelation analysis to study precipitation variability. It was found that autocorrelation of precipitation measurements drop to 0.45 and 0.58 in 10 minutes time for 4 and $8 \mathrm{~km}$ pixel, respectively. Similarly spatial autocorrelation drops to 0.64 and 0.61 for $4 \mathrm{~km}$ pixel with $4 \mathrm{~km}$ displacement and $8 \mathrm{~km}$ pixel with $8 \mathrm{~km}$ displacement, respectively. The drop in autocorrelation in the spatiotemporal series is shown to be even more rapid. The root mean square fractional error for precipitation shows a value of 0.63 to 0.90 and 0.71 to 0.94 for 10 to 60 minute time lag for 4 and $8 \mathrm{~km}$ pixel, respectively. The autocorrelation analysis of precipitation underlines the need for precise geolocation and time measurement at each pixel for meaningful intercomparison. We have also presented results on the precipitation comparison when two observations have different spatial scales. We analyzed the probability distribution $P\left(r_{i} \mid R\right)$, of precipitation measurements $r_{i}$ at $2 \mathrm{~km}$ scale within a $8 \mathrm{~km}$ pixel for a given pixel averaged rain rate $R$. It was found that there is only $40 \%$ probability that a 2 and $8 \mathrm{~km}$ pixel averaged rain will match with a percentage error less than $50 \%$ of $R$. We also presented a Monte Carlo simulated precipitation comparison measured at two different scales 8 and $2 \mathrm{~km}$. This analysis highlights the importance of the comparable scales in precipitation validation.
\end{abstract}

\section{Introduction}

Precipitation measurement products from satellite observations at infrared (IR) and microwave frequencies are becoming increasingly more sophisticated due to advancements in observational instruments and data fusion from various sources (e.g., satellite derived IR

Corresponding author: Atul Kumar Varma, Atmospheric and Oceanic Sciences Group, EPSA, Space Applications Centre (ISRO), Ahmedabad 380015, India

E-mail: avarma@sac.isro.gov.in

(C)2012, Meteorological Society of Japan and microwave, ground observations, model outputs, etc.). Equipped with better accuracy and wider coverage, the satellite derived precipitation products are fast becoming primary inputs to many hydrological and meteorological applications including numerical weather prediction (NWP), river discharge, surface water runoff, flash flood, soil moisture, etc. The satellite microwave based rainfall retrieval methods for direct interaction to hydrometeors are considered to be superior to IR based methods because IR radiation cannot penetrate the clouds and rain measurement systems using IR signals are always indirect in nature. On the 
other hand, passive microwave radiances interact with hydrometeors and hence they provide more direct measurement of rain. Despite fairly good understanding of radiative transfer through the atmosphere, the rain measurement from passive microwave measurements still remains a challenging task. One of challenges in the passive microwave retrieval of rain arises due to uncertainty in the horizontal and vertical distribution of rainfall within its large instantaneous field of view (IFOV), which is referred as the beam filling problem (Varma et al. 2004; Varma and Liu 2006). The horizontal rain variability within IFOV results in severe underestimation of precipitation, whereas vertical variability results in deviations from mean brightness temperature $\mathrm{Tb}$ versus rain rate relationship (Liu 2003). The another challenge is the accurate rain identification, especially at low rain rates, which is more ambiguous as a similar order of change in brightness temperature $\mathrm{Tb}$ is possible due to variations in surface and atmospheric parameters. The third important challenge arises due to dependency of the Tb-rain rate relationship on rain type without prior identification may lead to error in rain estimation (Varma and Liu 2010). Apart from these major challenges, there are also problems in the forward radiative transfer simulations due to uncertainty in the shape/size, velocity and temperature of the hydrometeors, deficiencies in the radiative transfer model formulations, sensor noise, sampling, etc (e.g., Rapp et al. 2009; Varma 2008). There are a number of algorithms exists for rain measurement from space using IR, microwave and blended techniques with varying accuracies (e.g., Ebert and Manton 1998; Smith et al. 1998; Adler et al. 2001; Scofield and Kuligowaski 2003; Spencer et al. 1989; Wilheit et al. 1991; Petty 1994; Kummerow et al. 2001; Varma et al. 2002).

The blended IR-microwave techniques were developed to take advantage of both the finer spatial and temporal resolution of IR measurements from geostationary platforms as well as more direct microwave observations of the hydrometeors. Apart from IR-microwave blended algorithms, recent advancements in IR based precipitation estimation methods utilize the ancillary datasets (like, radar, NWP model derived fields of atmospheric parameters, etc.) for more accurate precipitation detection estimation at very high spatial resolution (pixel-scale) and at satellite data acquisition frequency (15 minutes to half-hourly) for such applications where timeliness of the observations is of utmost importance (e.g., flash flood warning). However, the quantitative validation of such high spatial and temporal resolution measurements of precipitation poses a great challenge due to high variability of the natural precipitation. This is owing to the fact that rain statistics essentially depends upon spatial and temporal scales over which rain data is averaged (Kundu and Bell 2003). In this study, an attempt has been made to unravel the precipitation variability at a pixel scale to explore the validation accuracy of precipitation measured from geostationary satellites at pixel scale. We carry out this work considering precipitation measurements at IR pixel scale, e.g., the Hydro-Estimator technique that provides precipitation measurement at pixel-scale $(\sim 8 \mathrm{~km})$ every half hourly from Kalpana/ INSAT-1D satellite. The Hydro-Estimator method was initially developed at NOAA (Scofield and Kuligowaski 2003; Ramirez-Beltran et al. 2008), which provides pixel scale instantaneous estimation of the precipitation by blending IR measurements from geostationary satellite with NWP observations and earth's elevation model.

Precipitation is known to vary in all possible spatial scales ranging from a few meters to several kilometers (McCollum and Krajewski 1998; Tustison et al. 2003) posing a difficulty not only in the validation of the precipitation but also in its retrieval using satellite observations. Several researchers (e.g., Wilheit 1986; Chiu et al. 1990; Varma et al. 2004; Varma and Liu 2006) described and also suggested a possible stochastic solution to the beam filling problem that leads to severe underestimation of the precipitation at microwave frequencies. A number of researchers have examined the precipitation variability on a small scale and reported its spatial distribution as a lognormal distribution (e.g., Lopez 1976; Kedem and Slud 1994). Tustison et al. (2001, 2003) examined the scale dependency of the precipitation and the errors associated with them when interpolated from one scale to another. Gupta and Waymire (1993) examined the precipitation mesoscale variability and modeled the variability in short time intervals based on the concept of random cascades. Kundu and Bell (2003) tried to capture the spatial and temporal variability of the mesoscale rainfall in a stochastic model. A number of investigators tried to examine the temporal variability of the precipitation through autocorrelation analysis. For examples, Yule (1945) examined autocorrelation on annual precipitation data time series in Greenwich for the years 1815-1924 and found the autocorrelation coefficients in annual precipitation with lag 1 to 24 years varied from -0.12 to +0.19 .

Different satellite based retrieval algorithms have different theoretical accuracy which can only be brought out by the validation results. However, the validation results are not absolute, but depend upon rain 
variability and the measurement scale. Thus for absolute validation of satellite precipitation measurements, it is necessary to address the problem associated with satellite based pixel-scale instantaneous precipitation measurements that arises either due to misalignment in space and/or time of the two measurements under consideration for comparison or due to their different scales of measurement.

If root mean square error in the satellite measurements is $E_{0}$, scale mismatch is $E_{S}$, and space and time misalignment of observations is $E_{m}$, the total error $E$ can be expressed as:

$$
E=\sqrt{E_{0}^{2}+E_{S}^{2}+E_{m}^{2}}
$$

Here we assume that $E_{0}, E_{S}$ and $E_{m}$ are independent of each other. In the succeeding sections, we find that both $E_{S}$ and $E_{m}$ have potential to grow substantially, especially when scale or time/spatial difference between two observations is significant. The error in the satellite precipitation measurement $E_{0}$ also depends upon observation height. After falling from the base of the cloud, the raindrops undergo time/space displacement from the time they are observed by radar. They may also get partly or even fully evaporated if the relative humidity below the cloud is low. However, in the present study, we utilized the radar data only to generate pixels of different sizes and hence $E_{0}$ is always zero. The scale dependent and space/time misalignment error are examined in Subsection 3.1 and 3.2, respectively. We have described the data and analysis, and thereby derived results and conclusions in following sections of this paper.

\section{Data}

TOGA-COARE (Tropical Ocean Global Atmosphere Coupled Ocean-Atmosphere Response Experiment) (Webster and Lukas 1992) IOP (Intensive Observation Period) were held in Western Pacific warm pool from November 1992 to February 1993. The principal objective of this experiment was to understand the interactions between ocean surface and the tropical atmosphere. Data used in the present study are rain maps from the Massachusetts Institute of Technology (MIT) C- band Doppler radar, which was one of the two radars used in TOGA-COARE experiment. The TOGA-COARE surface rain radar data described by Short et al. (1997) were collected from two $5-\mathrm{cm}$ shipboard Doppler weather radars by NASA and MIT, which were located in the Pacific warm pool region at approximately $2^{\circ} \mathrm{S}, 154.5^{\circ} \mathrm{E}$ and $2^{\circ} \mathrm{S}, 156^{\circ} \mathrm{E}$, respectively (Fig. 1). The NASA/TOGA radar was on board the People's Republic of China's research vessel

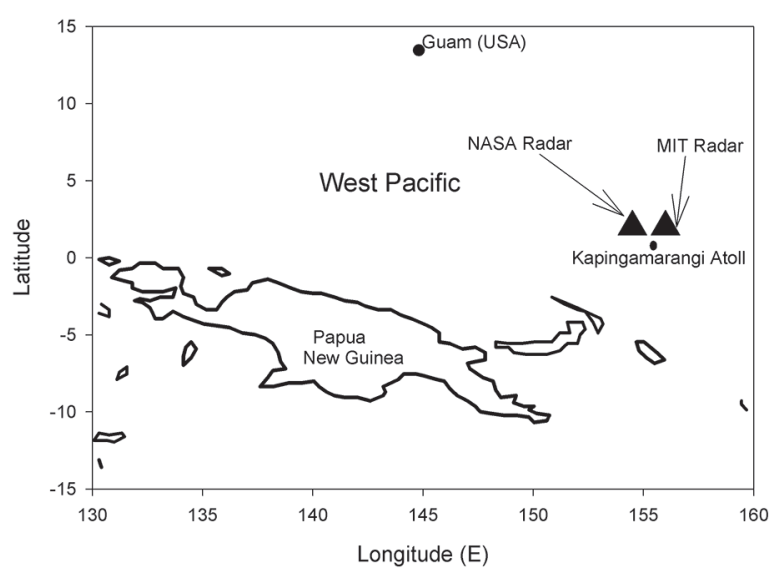

Fig. 1. Geolocation of TOGA-COARE Radars.

Xiangyanghong 5 and the MIT radar was on board the US research vessel John V. Vickers. During the period of their deployment, both the radars operated 24 hours a day, and it was ensured that at least one of the radars provide continuous sampling of precipitation. The radar reflectivities were measured every $10 \mathrm{~min}$ at a scan height of $2 \mathrm{~km}$. In order to reduce the effects of random error, a Cartesian sub-resolution sampling scheme was used to average $8 \times 8$ arrays of raw data onto a 2-km grid (Short et al. 1997). The radar reflectivity versus rain rate $(Z-R)$ relation was derived by calibrating the radar measurements against disdrometer data from Kapingamarangi Atoll (Fig. 1) in the Federated States of Micronesia in the Pacific. The TOGACOARE observations were obtained during three ship cruises; cruise 1 from 10 Nov. to 10 Dec. 1992, the cruise 2 from 15 Dec. 1992 to 18 Jan. 1993, and cruise 3 from 23 Jan. to 23 Feb. 1993. The number of days in each cruise was 30,35 , and 32 days, respectively. During cruise 1, 2 and 3 the average rainfall reported was 3.4, 6.6 and $3.8 \mathrm{~mm} \mathrm{day}^{-1}$ respectively, and the wettest periods were during 23-24 Nov 1992, 20-25 Dec 1992 and 18-19 Feb 1993, respectively (Short et al. 1997). The overall average rain rate observed during TOGA-COARE was $4.8 \mathrm{~mm}$ day $^{-1}$. The data TOGA-COARE radar data available with us does not include rain-type classification. In the tropics most rain has convective origin (Houze 1997). This is also evident during the TOGA-COARE IOP-1, 2 and 3 when the contribution of the convective rain was found to be $80 \%, 71 \%$ and $72 \%$, respectively (Shorts et al. 1997). The TOGA-COARE data were extensively used for a number of studies in the past and to our knowledge is the only campaign over the intensively rainy oceanic 
area (warm pool region) that extended to about 100 days (10 Nov 1992 to 23 Feb 1993) with 10 minutes observations. The wealth of data led us to use it in the present study. In this study, the available data only from MIT radar collected during cruise 1 and cruise 2 are used.

\section{Analysis and Results}

In order to examine the accuracy of the precipitation measurements from satellite observations, comparisons with concurrent ground truth measurements are performed. The ground truth measurements do not truly represent the satellite observations when they are spatially or temporally misaligned or taken at different scales. This result in so-called representativeness error in the satellite measurement validation, which, herein, we try to examine through the temporal/spatial variability of the precipitation manifested in the autocorrelation analysis of the temporal/spatial precipitation series. This study provides an insight to the precipitation validation when the ground truth observations are at the same spatial scale as satellite observations but slightly shifted in space and/or time domain. We have also carried out and presented error analysis for such measurements. This study, however, does not encompass all cases of comparison studies, like those in which the ground truth observation represents a smaller area and often just a point measurement. For such measurements, we examine and present the effect of rain measured at two different scales on comparison results.

In order to carry out the present study, we essentially focus upon two characteristics of the pixel-scale instantaneous precipitation: the de-correlation time or spatial scale of the precipitation and sub-pixel rain variability. For both studies, the results are generated considering pixel sizes of $8 \mathrm{~km} \times 8 \mathrm{~km}$ and $4 \mathrm{~km} \times 4 \mathrm{~km}$ that roughly represent the instantaneous field of view of the presently available IR measurements from geostationary satellites like Kalpana, INSAT, Meteosat, etc. The study is carried out using TOGA-COARE radar observations available every 10 minutes at $2 \mathrm{~km} \times 2$ $\mathrm{km}$ spatial resolution over an image area comprising of $278 \times 278$ pixels. Considering resolution of the present day IR images from geostationary satellites, we average $2 \times 2$ and $4 \times 4$ pixels to produce radar images at $4 \mathrm{~km} \times 4 \mathrm{~km}$ and $8 \mathrm{~km} \times 8 \mathrm{~km}$ resolutions. In this paper we refer original $2 \mathrm{~km} \times 2 \mathrm{~km}$ native pixel and averaged $4 \mathrm{~km} \times 4 \mathrm{~km}$ and $8 \mathrm{~km} \times 8 \mathrm{~km}$ pixel as $2 \mathrm{~km}$, $4 \mathrm{~km}$ and $8 \mathrm{~km}$ pixel or scale.

\subsection{Temporal, spatial and spatiotemporal analysis of pixel-scale precipitation}

We carried out autocorrelation of spatial, temporal and spatiotemporal series for precipitation. For generating precipitation time series, while averaging the pixels, we move 1 native $2 \mathrm{~km}$ pixel at a time from west to east or north to south to generate a large number of averaged pixels to follow them in subsequent images. We locate a rain pixel in an image and then follow that in subsequent images for the next $24 \mathrm{hrs}$. As the ships slightly drift with time due to wind action and ocean currents, a pixel under consideration is also shifted in subsequent images, and hence we spatially collocate the pixel in the subsequent images to generate a rain time series that the pixel represents. We follow the same procedure for all pixels of that image of which there are nearly 20,000 in number. Out of 20,000 pixels about $60 \%$ pixels are found to have continuous valid observations for 24 hours. We, however, consider only those time series for which observations are available for 24 uninterrupted hours (no missing observations), and rain is present at initial time step and the accumulated rain for the series is $>5 \mathrm{~mm}$. We then proceed to generate another set of time series that have an initial start time after 24 hours. This procedure is followed for the entire period of cruise 1 and cruise 2 of TOGA-COARE observations. Cruise 1 last for 30 days, i.e., 14880 thousands of samples, cruise 2 was for 35 days, i.e., around 16320 thousands of samples so as a whole we used 31200 thousands samples for this study. To generate spatial precipitation series we scan each image averaged to $4 \mathrm{~km}$ or $8 \mathrm{~km}$ spatial resolution for the presence of rainy pixel and then move in the east, north, west and south directions to follow the rain and generate a spatial series for further processing if continuous valid pixels are available for about $200 \mathrm{~km}$ in any direction. The choice of 24 hours for the time series and $200 \mathrm{~km}$ for the spatial series is arbitrary, but it is to ensure a sufficiently long time/spatial precipitation series. Apart from studying temporal and spatial variability of rain we also attempted a spatiotemporal variability study of precipitation, which is carried out with both $8 \mathrm{~km}$ and $4 \mathrm{~km}$ pixels. For this study, we generated a time series for 24 hours continuous of observations in which a pixel from the subsequent images was shifted by $2 \mathrm{~km}$ and $4 \mathrm{~km}$ from the previous image. By following this process, we got a series with spatiotemporal lag of $10 \mathrm{~min}$ and displacement of $2 \mathrm{~km}$, and lag of $10 \mathrm{~min}$ and displacement of $4 \mathrm{~km}$. This procedure was followed for all rainy pixels encountered. All temporal, spatial and spatiotemporal series generated with above described procedure are subjected to autocorrelation 
analysis. Assuming stationarity of the time/spatial series, the autocorrelation function of such series is given by (Anderson 1971):

$$
\rho(k)=\frac{\sigma(k)}{\sigma(0)},
$$

where $k$ is the lag and $\sigma(k)$ is the autocovariance function for lag $k$ and is given by,

$$
\sigma(k)=\frac{1}{n-k} \sum_{i=1}^{n-k}\left(X_{i}-\mu\right)\left(X_{i+k}-\mu\right),
$$

where $\mu$ is the mean of the time/spatial series.

For autocorrelation studies of temporal, spatial and spatiotemporal precipitation series, we examined the data series from cruise 1 and cruise 2 of TOGACOARE period. For each of the cruises, we subjected all available precipitation (time/spatial/spatiotemporal) series to autocorrelation analysis and averaged resulting individual autocorrelation profiles to generate a single averaged autocorrelation profile specific to that cruise. Figure 2a shows the variation in the averaged autocorrelation function of rain measured over $4 \mathrm{~km}$ (solid symbols) and $8 \mathrm{~km}$ pixel (open symbols) with a time lag of 10 minutes for the rain events during cruise 1 (i.e., 10 Nov to 11 Dec 1992), cruise 2 (i.e., 15 Dec. 1992 to 18 Jan. 1993) and total period (i.e., 10 Nov. 1992 to 18 Jan 1993). All the plots in Fig. 2a show sharp drop in the autocorrelation function indicating that rain at any time step is poorly correlated to rain in the neighboring time step. The plots of the autocorrelation function with time are nearly similar for rain measured over a given area; they however, differ slightly for rain measured over $4 \mathrm{~km}$ and $8 \mathrm{~km}$ pixels. The drops in the autocorrelation function in Fig. 2a for $4 \mathrm{~km}$ are steeper than that for $8 \mathrm{~km}$ pixel, which indicate that precipitation averaged over a larger footprint is more closely related to precipitation measured at a neighboring time step than that averaged over smaller footprint. All the plots presented in Fig. $2 \mathrm{a}$ are subjected to uncertainty analysis by calculating the $90 \%$ confidence intervals, which are found to be negligibly small. This is mainly due to fact that each value plotted in Fig. 2a is derived by averaging a large number $(\sim 10 \mathrm{~K}-15 \mathrm{~K})$ of autocorrelation profiles from individual pixels. The small values in confidence intervals indicate a very stable relationship between the autocorrelation function and time lag plotted in Fig. 2a. Figure $2 \mathrm{a}$ indicates that autocorrelation function for 4 $\mathrm{km}$ pixel drops to about 0.45 and 0.24 in 10 and 20 minutes respectively, whereas that for $8 \mathrm{~km}$ pixel drops to about 0.58 and 0.37 during same period. We find the decorrelation time (time in which autocorrelation
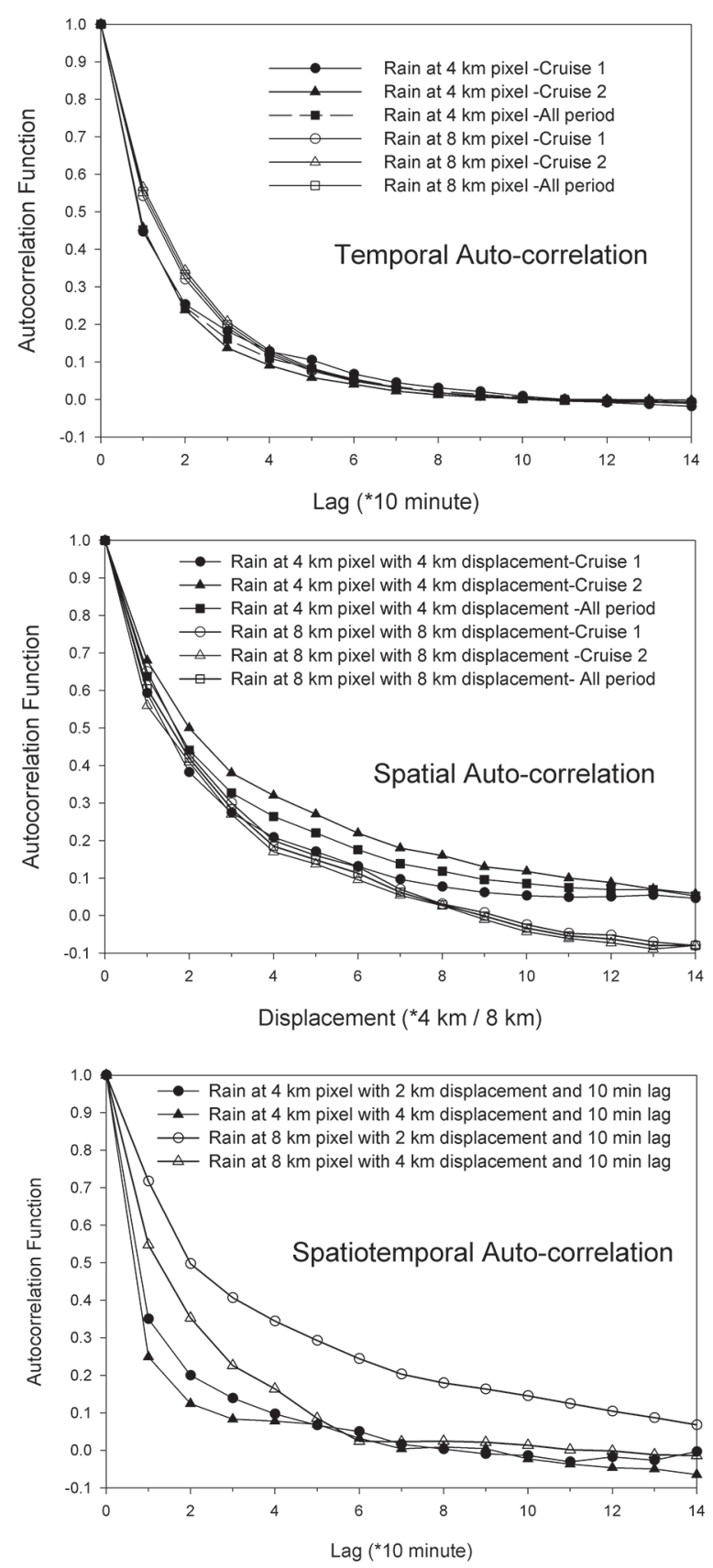

Fig. 2. Variation of autocorrelation of precipitation for measurements, during TOGA-COARE cruise 1 (circle), cruise 2 (triangle) and during the combined period (square) with (a) time lag of 10 minutes (b) spatial displacement of $4 \mathrm{~km}$ and $8 \mathrm{~km}$, and (c) for spatiotemporal displacement of $2 \mathrm{~km}$ (circle) and $4 \mathrm{~km}$ (triangle), and time lag of 10 minutes, with solid symbols represent the $4 \mathrm{~km} \times 4 \mathrm{~km}$ pixel and open symbols represent for $8 \mathrm{~km} \times 8 \mathrm{~km}$ pixel. 
function drops to 1/e) from Fig. 2a for $4 \mathrm{~km}$ and $8 \mathrm{~km}$ pixels as about 15 minute and 20 minute, respectively.

Similar to Fig. 2a, Fig. $2 \mathrm{~b}$ shows the drop in the autocorrelation function for precipitation averaged over 4 $\mathrm{km}$ (solid symbols) and $8 \mathrm{~km}$ (open symbols) with spatial displacement of $4 \mathrm{~km}$ and $8 \mathrm{~km}$, respectively, for 2 different cruises during TOGA-COARE period, separate and combined. A sharp drop in the autocorrelation function for rain in both $4 \mathrm{~km}$ and $8 \mathrm{~km}$ pixels indicate that rain is poorly correlated to rain occurring in the neighboring pixel. The plot for autocorrelation of rain for $4 \mathrm{~km}$ pixel for cruise 1 shows a steeper drop in the autocorrelation function than that for cruise 2 , which is not so obviously manifested in similar plots for $8 \mathrm{~km}$ pixel possibly because of its larger spatial area. A plausible reason may be that cruise 1 had highest number of convective rainfall $(80 \%)$ and the highest percentage of convective occurrences (Short et al. 1997) which may have resulted in higher spatial variability (Houze 1997; Varma and Liu 2006) which is manifested in the plot for $4 \mathrm{~km}$ pixel area. Like Fig. 2a, the $90 \%$ confidence intervals for plots in Fig. $2 \mathrm{~b}$ are found to be negligibly small and hence the relationships presented in Fig. $2 b$ between auto-correlation function and spatial displacements are highly stable. It may be noted from Fig. $2 b$ that autocorrelation of rain at $4 \mathrm{~km}$ pixel falls more rapidly than that for $8 \mathrm{~km}$. Figure $2 \mathrm{~b}$ shows precipitation averaged over a larger footprint does not just have a closer relationship with that measured in the previous time step (Fig. 2a), but is also has a closer relationship with that measured at the same spatial displacement. The averaged spatial rain autocorrelation for 2 cruises for $4 \mathrm{~km}$ pixel drops to 0.64 and 0.44 for a displacement of $4 \mathrm{~km}$ and $8 \mathrm{~km}$, respectively, and that for $8 \mathrm{~km}$ pixel drops to 0.61 and 0.42 for a displacement of $8 \mathrm{~km}$ and $16 \mathrm{~km}$, respectively. The decorrelation distance for precipitation is found to be about $10.5 \mathrm{~km}$ and $18.5 \mathrm{~km}$ for $4 \mathrm{~km}$ and $8 \mathrm{~km}$ pixel, respectively.

Figure 2c shows spatiotemporal autocorrelation of precipitation for $4 \mathrm{~km}$ pixel with a time lag of $10 \mathrm{~min}$ utes and spatial displacement of $2 \mathrm{~km}$ (sold circles) and $4 \mathrm{~km}$ (solid triangle). The similar plots for $8 \mathrm{~km}$ pixels are also shown in Fig. 2c with open symbols. The autocorrelation precipitation plots for $4 \mathrm{~km}$ pixel show a rapid drop to about 0.36 and 0.25 in 10 minutes for $2 \mathrm{~km}$ and $4 \mathrm{~km}$ spatial displacement, respectively. Figure $2 \mathrm{c}$ suggests that precipitation at any time step is decorrelated from the neighboring time step. For precipitation at $8 \mathrm{~km}$ pixel, the autocorrelation function drops to 0.75 and 0.55 in 10 minutes and 0.50 and 0.36 in 20 minutes for $2 \mathrm{~km}$ and $4 \mathrm{~km}$ of spatial displacement, respectively. The decorrelation time is 20 and 38

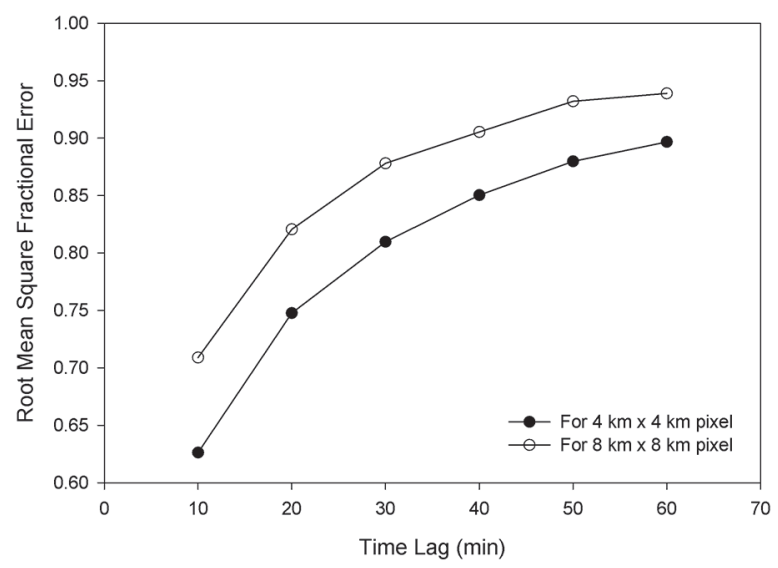

Fig. 3. Variation of root mean square fractional error with time lag for $4 \mathrm{~km} \times 4 \mathrm{~km}$ (solid circle) and $8 \mathrm{~km} \times 8 \mathrm{~km}$ (open circle) pixel.

minutes for precipitation at $8 \mathrm{~km}$ pixel with 2 and $4 \mathrm{~km}$ spatial displacement, respectively.

For the measurements that are separated in the time domain, we have calculated the root mean square fractional error RMSFE, which is given as,

$$
R M S F E=\sqrt{\frac{\sum_{i=1}^{n}\left(\frac{R i(t)-R i(t+\Delta t)}{R i(t)}\right)^{2}}{n}},
$$

where $R i(t)$ is rain measured at time $\mathrm{t}$ and $R i(t+\Delta t)$ is rain measured after time lag $\Delta t$ over the same area. We have calculated RMSFE for both $4 \mathrm{~km}$ and $8 \mathrm{~km}$ pixels and for a time lag $\Delta t$ of 10 minutes to $60 \mathrm{~min}$ utes, plotted in Fig. 3. The RMSFE is calculated when rain continues for the given time lag. From Fig. 3, it can be observed that RMSFE varies from 0.63 to 0.90 and from 0.71 to 0.94 for 10 minute to 60 minute lag for $4 \mathrm{~km}$ pixel and $8 \mathrm{~km}$ pixel, respectively. Thus compared to $4 \mathrm{~km}$ pixel, precipitation measured over 8 $\mathrm{km}$ pixel is more closely related with precipitation at the neighboring step but has a higher RMSFE, which indicates that lower rain rates are exhibited by rain averaged over a larger area (i.e., $8 \mathrm{~km}$ pixel) compared to rain averaged over smaller area (i.e., $4 \mathrm{~km}$ pixel). These results are consistent with those of Ryzhkov et al. (2005) who compared precipitation measured by radar with gauge data and found that fractional rmse are higher for lower rain values.

\subsection{Analysis of sub-pixel scale precipitation}

In Fig. 2, we have examined the precipitation autocorrelation measured over two different pixel sizes 4 
$\mathrm{km}$ and $8 \mathrm{~km}$. The study indicates the difficulty in validating the areal averaged satellite observations with identical resolution measurements from other means when the two observations do not coincide precisely. This study, however, does not address the problems that occur when the two observations under comparison have different spatial resolutions. Thus in the proceeding part of the study presented herein, we will examine the possible effect on validation when concurrent satellite and surface observations have different spatial resolutions. This is carried out by considering a window area of $8 \mathrm{~km} \times 8 \mathrm{~km}$ which is filled with 16 radar pixels of $2 \mathrm{~km} \times 2 \mathrm{~km}$ resolution. We moved this window in north-south and east-west directions over each of the radar images which are acquired during cruise 1 and cruise 2 of the TOGA-COARE. Whenever this window is filled with rain, we calculate average rain for the window and also calculated the distribution of the sub-window rain rates as given by $162 \mathrm{~km}$ resolution radar pixels. As all 16 radar pixels within an $8 \mathrm{~km} \times 8 \mathrm{~km}$ window do not always show rain, we have calculated fractional rain cover FRC within each window. The FRC is given as the fraction of raining pixels within a window. The relation between FRC and window averaged rain rate $R$ is given in Fig. 4, which shows an averaged $R$ in each FRC of 0.05 . The FRC reaches to 1 for an $R$ value of about $2.5 \mathrm{~mm} \mathrm{~h}^{-1}$. We further averaged the sub-window rain $r_{i}$ distributions for each $1 \mathrm{~mm} \mathrm{~h}^{-1}$ bins of the window averaged rain rate $R$. Figure 5 shows some of the conditional probability distributions of sub-window rain rates which are conditioned to window averaged rain rates. Though we have calculated conditional probability distributions of sub-window rain rates $r_{i}$ for each $1 \mathrm{~mm} \mathrm{~h}^{-1}$ bin of window averaged rain rates $R$ up to $30 \mathrm{~mm} \mathrm{~h}^{-1}$, for brevity only a few distributions are shown in Fig. 5. The conditional probability distributions of the sub-window rain rates are found to follow lognormal distribution, which is in agreement with past studies (e.g., Varma et al. 2004; Varma et al. 2006). The abscissa of Fig. 4 is thus plotted as natural logarithmic of sub-pixel rain $\ln$ $(r)$. Figure 5 shows a wide range of the possibility for sub-window rain rates in a given window averaged rain rate. The probability of sub-window rain rate matching with window averaged rain rate is small. We have calculated the probability $P(r \mid r(R, E))$ of sub-window rain rate when found within a given window averaged rain rate for plots shown in Fig. 5, presented in Fig. 6. For $R$ values below $2.5 \mathrm{~mm} \mathrm{~h}^{-1}$ we took FRC into consideration before arriving at $P(r \mid r(R, E))$. In other words, this is the probability when window averaged rain rate $R$ matches with sub-window rain rate $r$ with

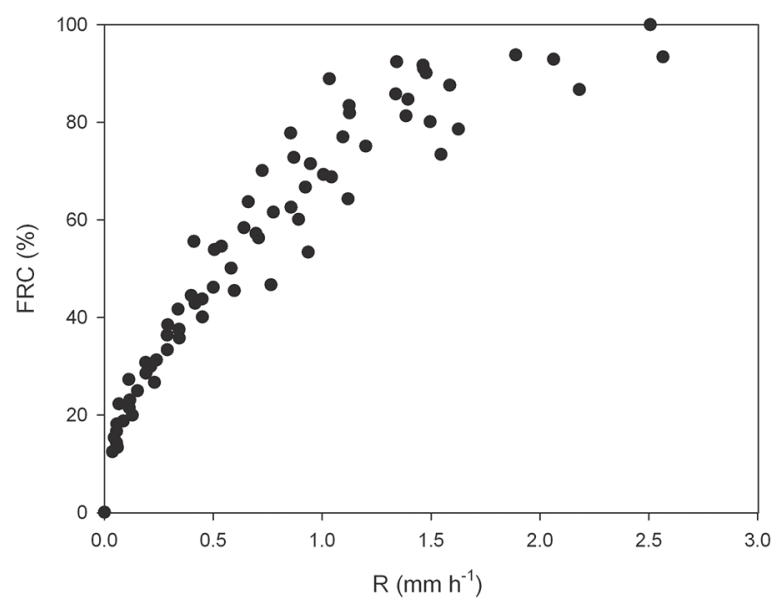

Fig. 4. Fractional Rain Cover FRC versus pixel averaged rain $\mathrm{R}$ which is averaged in each FRC bins of 0.5 .

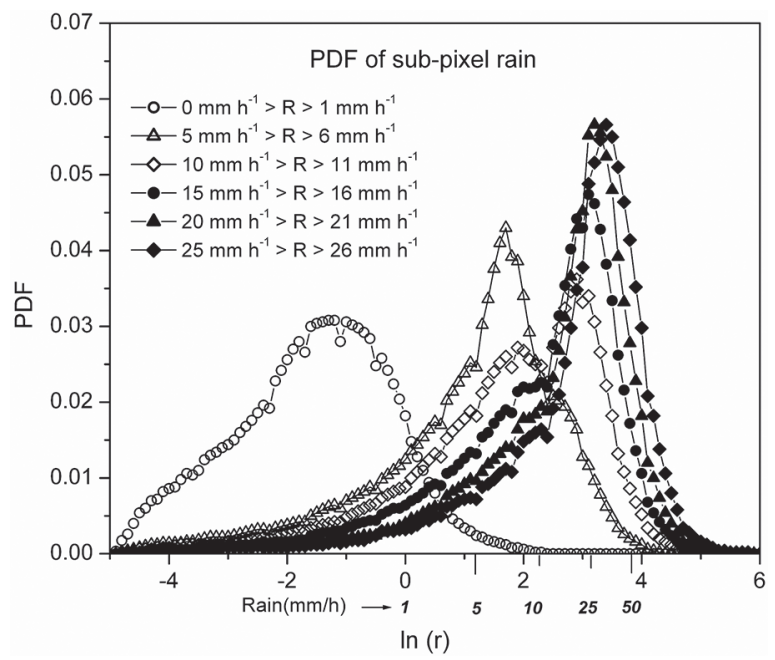

Fig. 5. Conditional Probability Distribution of rain rates $r_{i}$ over $2 \mathrm{~km} \times 2 \mathrm{~km}$ areas within $8 \mathrm{~km} \times 8 \mathrm{~km}$ pixel with pixel averaged rain rates $R$ bin of $>0-1,5-6,10-11$, 15-16, 20-21, 25-26 $\mathrm{mm} \mathrm{h}^{-1}$.

a percentage error $E$ such that $r$ lies in the range bin,

$$
R *\left(1-\frac{E}{100}\right)<r<R *\left(1+\frac{E}{100}\right)
$$

Figure 6 shows $P(r \mid r(R, E))$, which is the probability of $r$ when $r$ lies in a range defined by $R$ and $E$ in (4), plotted for some of the $R$ values as given in Fig. 5 and for $E$ (percentage error) values of 10, 25, 50, 75 and 100. Figure 6 shows that for all $R$ bins, $P(r \mid r(R, E))$ increases rapidly with $E$ in a near iden- 


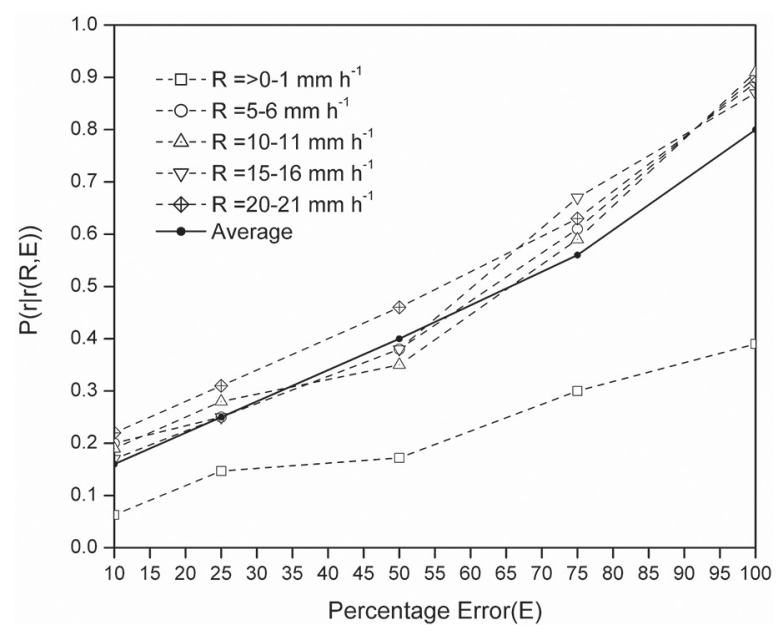

Fig. 6. Probability $P(r \mid r(R, E)$ of rain rate over $2 \mathrm{~km} \times 2$ $\mathrm{km}$ area when lying within a given percentage $E$ of pixel averaged rain rate $R$ calculated from Conditional Probability Distribution of rain rates plotted in Fig. 5.

tical manner except for cases of very low rain rates where FRC $<1$. Thus in general, we can describe the behavior of $P(r \mid r(R, E))$ with $E$ by an average plot also shown in Fig. 6 as a solid line. The average behavior of $P(r \mid r(R, E))$ gives the probability value of $0.19,0.29$, $0.40,0.64,0.90$ for sub-window rain rate matching with window average rain rate $R$ with percentage error of $10 \%, 25 \%, 50 \%, 75 \%$ and $100 \%$ of $R$, respectively. It may be noted that a percentage error of $100 \%$ of $R$ covers the entire lower range of precipitation (given by (4)), thus $10 \%$ of sub-window rain rates have $r>2 * R$.

We have further generated a Monte Carlo simulated scatter plot of the comparison of rain measured from a hypothetical satellite with $8 \mathrm{~km}$ pixel with ground observations at $2 \mathrm{~km}$ of resolution. The probability distribution of rain at $8 \mathrm{~km}$ is calculated by spatially averaging TOGA-COARE radar observations during cruise 1 and 2 and is provided in Fig. 7. Figure 7 shows the probability of precipitation is high for small rain rates and falls rapidly for higher rain rates. We simulated 100 thousand observations that have probability distribution as given in Fig. 7, with a pixel size of 8 $\mathrm{km}$. For each of the simulated precipitation values we calculated corresponding rain over a $2 \mathrm{~km}$ area with a random number with the same probability distribution as the sub-windows as discussed above and presented in Fig. 5. Figure 8 shows the Monte Carlo simulated scatter plot precipitation comparison from a hypothetical satellite at $8 \mathrm{~km}$ pixel resolution with a hypothetical ground observation at $2 \mathrm{~km}$ resolution. It may be

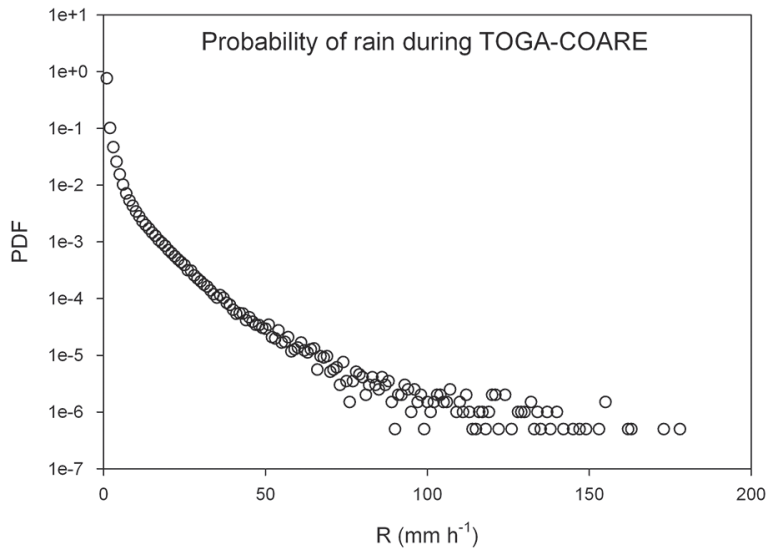

Fig. 7. Probability distribution of rain rates for $8 \mathrm{~km} \times 8$ $\mathrm{km}$ pixel during TOGA-COARE cruise 1 and 2.

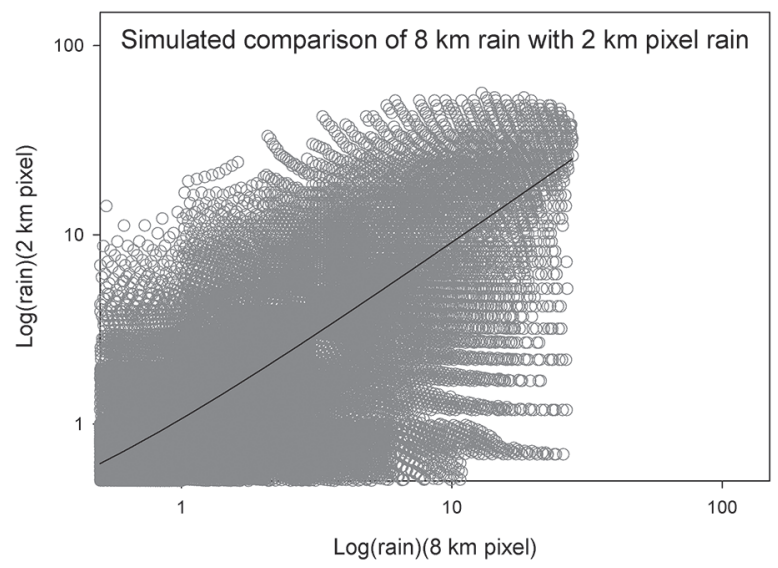

Fig. 8. A Monte Carlo Simulated comparison of rain over $8 \mathrm{~km} \times 8 \mathrm{~km}$ pixel with $2 \mathrm{~km} \times 2 \mathrm{~km}$ averaged rain using aprior probability distribution of rain $\mathrm{R}$ (as in Fig. 7) and Conditional Probability Distribution of rain rates $r_{i}$ (as some of them in Fig. 5).

noted here that the two simulated precipitation values plotted in Fig. 8 are simultaneous and the hypothetical ground observation is overlapped by corresponding hypothetical satellite observation. The comparison shows a correlation $R$ of 0.64 and error of estimation of $2.6 \mathrm{~mm} \mathrm{~h}^{-1}$ for a satellite precipitation measurement range of 0 to $50 \mathrm{~mm} \mathrm{~h}^{-1}$. We divide this whole range into three parts, light rain $\left(r<2.5 \mathrm{~mm} \mathrm{~h}^{-1}\right)$, moderate rain $\left(2.5 \mathrm{~mm} \mathrm{~h}^{-1}<r<10 \mathrm{~mm} \mathrm{~h}^{-1}\right)$, and heavy rain $(r$ $>10 \mathrm{~mm} \mathrm{~h}^{-1}$ ) (Varma and Liu 2006), and calculated error estimation for different ranges. The error of estimation for low, moderate and heavy rain is found to be 
$1.24,6.5$ and $14 \mathrm{~mm} \mathrm{~h}^{-1}$, respectively. The hypothetical ground based measurements show a much larger dynamic range compared to those of the hypothetical satellite measurements, which is due to the fact that higher rain rates are confined to smaller area with steep gradients (Goldhirsh and Walsh 1982).

\section{Conclusions}

In this paper, we have tried to demonstrate the uncertainties in validation of instantaneous precipitation when two measurements are in the same scale (8 $\mathrm{km}$ or $4 \mathrm{~km}$ ) but slightly shifted in space and/or in time. This is carried out by analyzing the autocorrelation of temporal, spatial and spatiotemporal series of precipitation at $4 \mathrm{~km}$ and $8 \mathrm{~km}$ scales. It was found that the autocorrelation function of precipitation measurements drop to 0.45 and 0.58 in 10 minutes time for $4 \mathrm{~km}$ and $8 \mathrm{~km}$ pixel, respectively. Similarly, spatial autocorrelation drops to 0.64 and 0.61 for $4 \mathrm{~km}$ pixel with $4 \mathrm{~km}$ displacement and $8 \mathrm{~km}$ pixel with $8 \mathrm{~km}$ displacement, respectively. The drop in autocorrelation in spatiotemporal series is shown to be even more rapid. The root mean square fractional error for precipitation shows a value of 0.63 to 0.90 and 0.71 to 0.94 for 10 to $60 \mathrm{~min}$ utes in time lag for $4 \mathrm{~km}$ and $8 \mathrm{~km}$ pixel, respectively. Thus the results show that a few minutes and/or few kilometer of difference in the alignment of two observations may have severe effects on validation results. This may happen when we compare satellite derived precipitation with radar observations which may not always be perfectly aligned in space and time due to inaccuracies present in their geolocation and time determination at each pixel. However, a proper care can be taken in geolocation and time determination to mitigate this problem.

The validation of area averaged precipitation is often more complicated. For example, in a satellite precipitation validation study the satellite and surface observation do not have the same spatial resolution. In the present study, we have tried to demonstrate the severity of this problem by specifying one of the observations as having a resolution of $8 \mathrm{~km}$ and another of 2 $\mathrm{km}$. We analyzed the probability distribution $P\left(r_{i} \mid R\right)$, of precipitation measurements $r_{i}$ at $2 \mathrm{~km}$ scale within an $8 \mathrm{~km}$ pixel for a given pixel averaged rain rate $R$. It was found that there is only $40 \%$ probability that a 2 $\mathrm{km}$ pixel averaged rain matches with $8 \mathrm{~km}$ pixel averaged rain with an error percentage less than $50 \%$ of $8 \mathrm{~km}$ pixel averaged rain $R$. We have also presented a Monte Carlo simulated comparison of precipitation data measured at two different scales $8 \mathrm{~km}$ and $2 \mathrm{~km}$. The results presented herein with $8 \mathrm{~km}$ and $2 \mathrm{~km}$ pixels do not represent a practical situation because ground observations are often just one or a few observation points distributed over a satellite footprint. But with the available TOGA-COARE data, we utilize surface precipitation data with a resolution below $2 \mathrm{~km}$. This study is only to highlight problem associated with validation when surface observation represents a much smaller area compared to the satellite foot print. The observation points, when compared with satellite observations may have a much more severe problem than what we have presented here. The results that are presented here have not taken into consideration the different measurement errors in individual observations. Hence in the real situation when we have point observations and satellite observations with different instrument/retrieval error characteristics together with small errors in geolocation and time determination, we would expect an even poorer comparison. In the present study the rain type/regime is also important but the rain type classification was not available. The TOGACOARE region is located in the warm pool region with most of the rain reported as convective (Short et al. 1997) during the experiment, which also supports the notion that tropical rain is mostly convective by origin (Houze 1997). This notion may not be applicable to higher latitudes and hence the present study may only be applicable to the tropical oceanic rain. It needs to be examined for its applicability for regions outside the tropics. We are continuing our efforts to unravel the effect of the density and distribution of rain gauge observations over satellite footprint on validation results, and the outcome of which will be presented in the future.

\section{Acknowledgement}

Authors are thankful to Director SAC for his encouragement. GL's participation to this study has been supported by NASA PMM grant NNX10AG76G and NSF grant AGS-1037936.

\section{References}

Adler, R.F., C. Kidd, G. Petty, M. Morrissey, and H. M. Goodman, 2001: Intercomparison of global precipita-tion products: The third Precipitation Intercomparison Project (PIP-3), Bull. Amer. Meteor. Soc., 82, 1377-1396.

Anderson, T. W., 1971: The Statistical Analysis of Time Series, New York: John Wiley \& Sons, 750p.

Barrett, E. C., and D. W. Martin, 1981: The use of satellite data in rainfall monitoring, p. 340. Academic Press, London.

Chiu, L. S., G. R. North, A. S. David, and A. McContell, 
1990: Rain estimation from satellites effects of finite field of view, J. Geophys. Res., 95, 2177-2185.

Ebert, E. E., and M. J. Manton, 1998: Performance of satellite based algorithms during TOGA COARE. $J$. Atmos. Sci., 55, 1537-1557.

Gupta, V. K., and E. Waymire, 1993: A statistical analysis of mesoscale rainfall as a random cascade. J. Appl. Meteorol. 32, 251-267.

Goldhirsh, J., and E. J. Walsh, 1982: Rain measurements from space using a modified Seasat-type radar altimeter, IEEE Trans. Antennas Propag., AP-30, 726-733.

Houze, R. A., Jr., 1997: Stratiform precipitation in regions of convection: A meteorological paradox? Bull. Amer. Meteor. Soc., 78, 2179-2196.

Kedem, B., and E. Slud, 1994; Partial Likelihood Analysis of Logistics Regression and Autoregression, Statistica Sinica, 4, 89-106.

Kummerow, C., and Coauthors, 2001: The evolution of the Goddard profiling algorithm (GPROF) for rainfall estimation from passive microwave sensors. J. Appl. Meteorol., 39, 1801-1820.

Kundu, P. K., and T. L. Bell, 2003: A stochastic model of space-time variability of mesoscale rainfall: Statistics of spatial averages, Water Resour. Res., 39, 1328, doi:10.1209.2002WR001802.

Liu, G., 2003: Determination of cloud and precipitation characteristics in the monsoon region using satellite microwave and infrared observations, Mausam, 54, 51-66.

Lopez, R. E., 1976: Radar characteristics of the cloud populations of tropical disturbances in the northwest Atlantic, Mon. Wea. Rev., 104, 268-283.

McCollum, J. R., and W. F. Krajewski, 1998: Investigations of error sources of the Global Precipitation Climatology Project emission algorithm, J. Geophys. Res., 103, 28,711-28,719, doi:10.1029/98JD02580.

Petty, G. W., 1994: Physical retrievals and latent heating distributions from satellite microwave radiometry. Part II: Algorithms Implimentation, Meteor. Atmos. Phys., 54, 101-122, doi:10.1007/BF01030054.

Ramirez-Beltran, N. D., R. J. Kuligowski, E. W. Harmsen, J. M. Castro, S. Cruz-Pol, and M. J. Cardona, 2008, Rainfall estimation from convective storms using the hydro-estimator and NEXRAD, WSEAS Transactions on Systems, 7, 1016-1027

Rapp, A. D., M. Lebsock, and C. Kummerow, 2009: On the consequences of resampling microwave radiometer observations for use in retrieval algorithms, Journal of Applied Meteorology and Climatology, 48, 19811993.

Scofield, R. A., and R. J. Kuligowaski, 2003: Status and outlook of operational satellite precipitation algorithms for extreme-precipitation events, Wea. Forecasting, 18, 1037-1051.

Short, D. A., P. A. Kucera, B. S. Ferrier, J. C. Gerlach, S.A. Rutledge, and O. W. Thiele, 1997: Shipboard radar rainfall patterns within the TOGA COARE IFA, Bull.
Amer. Meteor. Soc., 78, 2817-2836.

Smith, E. A., J. E. Lamm, R. Adler, K. Alishouse, E. Aonashi, E. Barrett, P. Bauer, W. Berg, A. Chang, R. Ferraro, J. Ferriday, S. Goodman, N. Grody, C. Kidd, D. Kniveton, C. Kummerow, G. Liu, F. Marzano, A. Mugnai, W. Olson, G. Petty, A. Shibata, R. Spencer, F. Wentz, T. Wilheit, and E. Zipser, 1998: Results of WetNet PIP-2 project. J. Atmos. Science, 55, 1483-1536.

Spencer, R. W., H. M. Goodman, and R. E. Hood, 1989: Precipitation retrieval over land and ocean with the SSM/I: Identification and characteristics of the scattering signal. J. Atmos. Oceanic Technol., 6, 254-273

Tustison, B., D. Harris, and E. Foufoula-Georgiou, 2001: Scale issues in verification of precipitation forecasts, J. Geophys. Res., 106, 11,775-11,784

Tustison, B., E. Foufoula-Georgiou, and D. Harris, 2003: Scale-recursive estimation for multisensory Quantitative Precipitation forecast verification: A preliminary assessment, J. Geophys. Res., 107, 8377, doi:10.1029/2001JD001073.

Varma, A. K., 2008: Satellite Microwave Measurement of the Precipitation: Some of the problems and their mitigation, ISRO-NOAA-SSEC Workshop on "Atmospheric Remote Sensing from Space Platforms", Vol. 1, 7-12 April, 2008, SAC, Ahmedabad, pp 98-115.

Varma, A. K., R. M. Gairola, S. Pokhrel, A. K. Mathur, B. S. Gohil, and V. K. Agarwal, 2002: Rain Rate Measurements over global oceans from IRS-P4 MSMR, Proceedings of Indian Academy of Sciences - Earth and Planetary Sciences, 111, 257-266.

Varma, A. K., G. Liu, and Y. J. Noh, 2004: Sub-pixel scale variability of rainfall and Its application to mitigate the beam-filling problem, J. Geophys. Res., 109, D18210, doi:10.1029/2004JD004968.

Varma, A. K., and G. Liu, 2006: Small scale horizontal rainrate variability observed by satellite, Mon. Wea. Rev, 134, 2722-2733. doi: 10.1175/MWR3185.1

Varma, A. K., and G. Liu, 2010: On classifying rain type using satellite microwave observations, J. Geophys. Res., 115, DO7204, doi:10. 1029/2009J12058.

Webster, P. J., and R. Lukas, 1992: TOGA COARE: The Coupled Ocean-Atmosphere Response Experiment. Bull. Amer. Meteor. Soc., 73, 1377-1416

Wilheit, T. T., 1986: Some comments on passive microwave measurement of rain. Bull. Amer. Meteor. Soc., 67, 1226-1232.

Wilheit, T. T., A. T. C. Chang, and L. S. Chiu, 1991: Retrieval of monthly rainfall indices from microwave radiometric measurements using probability distribution function. J. Atmos. Oceanic Technol., 8, 118-136.

Yule, G. U., 1945: On the method of studying time-series based on their internal correlations, Journal of Royal Statistical Society, 108, 208-225.

Ryzhkov, A. V., S. E. Giangrande, and T. J. Schuur, 2004: Rainfall estimation with a polarimetric prototype of WSR-88D, J. Appl. Meteorol., 44, 502-515. 